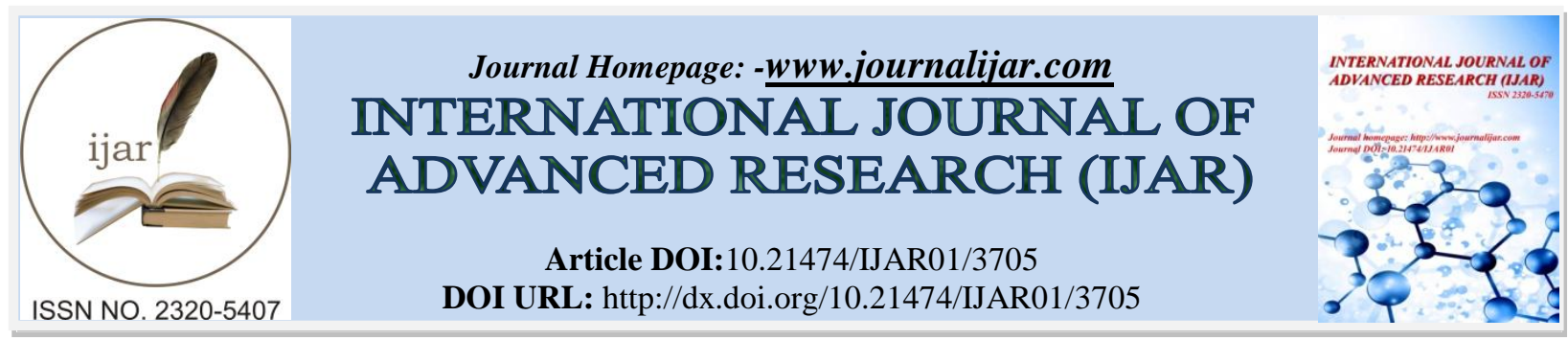

RESEARCH ARTICLE

\title{
THE EFFECTIVENESS OF USINGVIRTUAL MATHEMATICS LABORATORIES (VML) IN UBIQUITOUS LEARNING ENVIRONMENTS.
}

Elsaeed Elsaeed Mohamed Abd Elrazek ${ }^{1}$ and Rania Amid Abo Galala ${ }^{2}$.

1. Computer Teacher Preparation Department, Faculty of specific education, Damietta University, Egypt.

2. Lecturer, Computer Teacher Preparation Department, Faculty of Specific Education- Damietta University.

\section{Manuscript Info}

Manuscript History

Received: 14 January 2017

Final Accepted: 11 February 2017

Published: March 2017

Key words:-

Virtual Mathematics Lab (VML),

Ubiquitous learning,Acadox

environment Navigator \& develop

mathematical concepts

\begin{abstract}
The purpose of this study was measuring the effectiveness of using Virtual Mathematics Lab (VML) to improve teaching and learning of calculus. For learning calculus in VML mathematics classroom is proposed that describes the interactions among the students, VML, and the learning tasks, and how they lead to the learning of calculus. A design experiment was conducted in a class of 50 students from a secondary school. Use of VML was integrated into the teaching and learning of calculus concepts in the classroom with the aid of Acadox environment Navigator, a wireless classroom network system that enables instant and active interaction between students and teachers. It was found that the appropriate use of graphical, numerical and algebraic representations of calculus concepts using VML enabled students to better visualize the concepts and make generalizations about relevant mathematical properties. In addition, the students were able to link multiple representations, especially algebraic and graphical representations, to improve their conceptual understanding and problem-solving skills. VML was used as an exploratory tool, graphing tool, confirmatory tool, problem-solving tool, visualization tool and calculation tool. This suggests that VML is a multidimensional tool that supports mathematics learning. Overall, the findings of the study indicate that VML is an effective tool to develop mathematical concepts and promote learning and problem solving.
\end{abstract}

Copy Right, IJAR, 2017,. All rights reserved.

\section{Introduction:-}

The graphing calculator has been widely used as a technological tool in teaching and learning mathematics. There is a growing body of research which shows that the pedagogical affordances of the graphing calculator have a close relationship with improving learning of mathematics. Indeed, mathematics can be taught in a more coherent way by providing students with the opportunities to connect mathematical concepts within and between topics, and here the graphing calculator is well-positioned to offer a learning environment that enables mathematics to be experienced through multiple representations [1].

The curriculum standards of the National Council of Teachers of Mathematics[2] Suggest the use of graphing calculators to provide students with multiple representations to explore and investigate mathematical concepts. Extensive research has been conducted to answer questions such as whether graphing calculators significantly 
improve mathematical learning and problem solving [3]. However, many such studies have compared the use of graphing calculators to traditional chalk-and-talk learning, and little research has examined how students use graphing calculators in learning and the relationship between pedagogical strategies for learning and the use of graphing calculators.

Chu \& et al. Out an extensive review of research on graphing calculators, they found that certain teaching styles, such as interactive and inquiry oriented, are more compatible with the use of graphing calculators than others. However, they also point out that many studies fail to address the use of graphing calculators in an instruction context, which leads to inconsistent findings on their effectiveness in teaching and learning. This review suggests a need for studies that address the use of graphing calculators in an instruction context within a particular learning environment [4].

Accordingly, the purpose of this study was to investigate how the use ofVML, an advanced graphing calculator, could enhance teaching and learning of calculus. This article provides the details and results of a designed experiment, which involved the design and conduct of a VML for a class of 50 Secondary students. Use of VML was integrated into the teaching and learning of calculus concepts with the Acadox environment Navigator

\section{Conceptual Frameworks:-}

In the literature of mathematics reform, learning mathematics is viewed as a social endeavor, with the mathematics classroom functioning as a community in which thinking, presenting, talking, agreeing and disagreeing are encouraged [5]. Mathematical tasks are given to students to develop and extend their mathematical thinking and problem-solving ability. Student interaction with mathematical tasks and tools encourages them to construct mathematical ideas. Hence, create meaning for their learning.

Hwang Et Al. [6] observed that students should construct meaning from the tools that they use and the mathematical tasks in which they are engaged. They elaborated that learners construct mathematical meanings from tools as they use them. This leads to meaningful learning, as the tools become intertwined with the mathematical tasks. Bruce [7] pointed out that the quality of mathematics tasks is important in determining whether a task engages students and whether they attain higher order learning by being given opportunities to explain and justify their reasoning.

It is widely acknowledged that calculus concepts are abstract and complex for students and that teaching and learning these concepts can be challenging and even exasperating at times. Research has shown that many students have difficulties in learning the key concepts of calculus. It does not help that traditional calculus courses tend to focus on algebraic drills and the practicing of calculus problems without generating an understanding of the underlying concepts.

Specifically, in terms of calculus, many researchers have advocated that teaching and learning should focus on concepts, rather than simply techniques to improve student performance. Tall emphasized the need to help students move flexibly from one representation to another in learning calculus. Using a graphing calculator extends the teaching and learning of calculus concepts from being based solely on algebraic methods to the incorporation of numeric, algebraic and graphical representations. The idea of using the graphing calculator to provide a better connection between algebraic and graphical representations of calculus has been reported in several studies.

It is believed that the use of technology in the teaching of calculus can be beneficial if it is accompanied with appropriately designed activities. Lazonderet al.[8] highlighted that mathematical tools are important in helping students to make connections to build their mathematical understanding. Activities such as guided discovery and inquiry learning have been used in the design of worksheets to encourage interaction with graphing calculators to help students develop an understanding of calculus concepts.

In this study, many activities using Acadox environment were designed by the author, with inputs from the teacher of the participating class, hereafter the participating teacher, to provide students with opportunities to explore, generalize mathematical concepts, to help them develop confidence and ability in communicating mathematically. The preliminary framework for the use of VML in the intervention programme is an adaptation. 


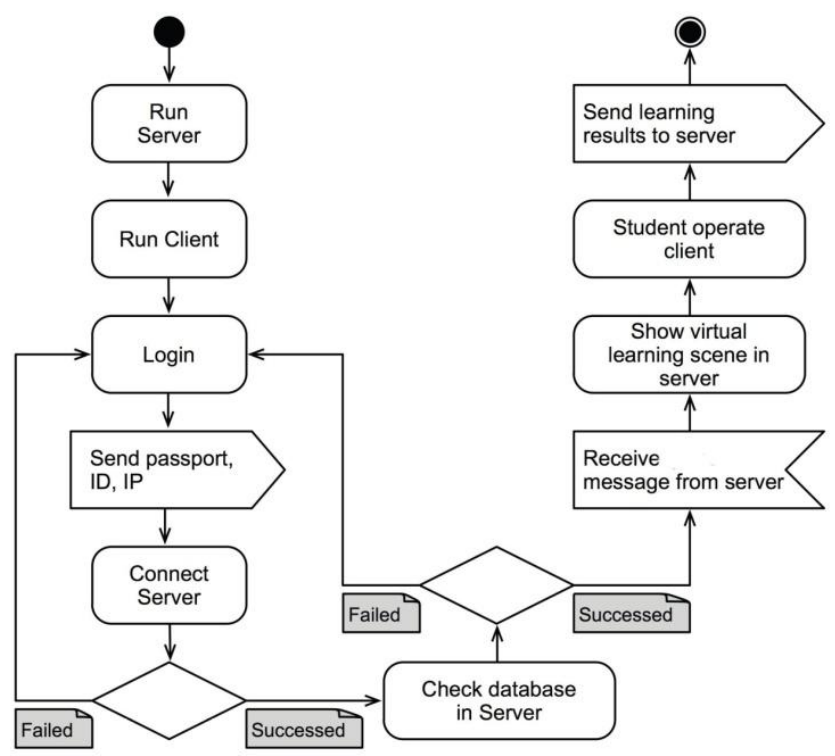

Fig. 1:- the steps to enter the student for Acadox environment.

A conceptual framework for calculus learning and teaching using Acadox environment was devised based on the foregoing literature review, and is illustrated in Fig. 2 This study seeks to the interactions among the students, VML, and the learning tasks lead to the learning of calculus. It describes Student Guided discovery and inquirybased design learning tasks VML with acadox environment

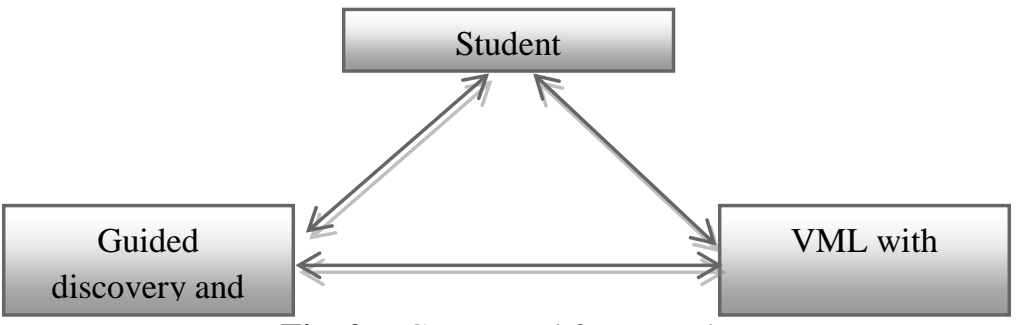

Fig. 2:- Conceptual framework.

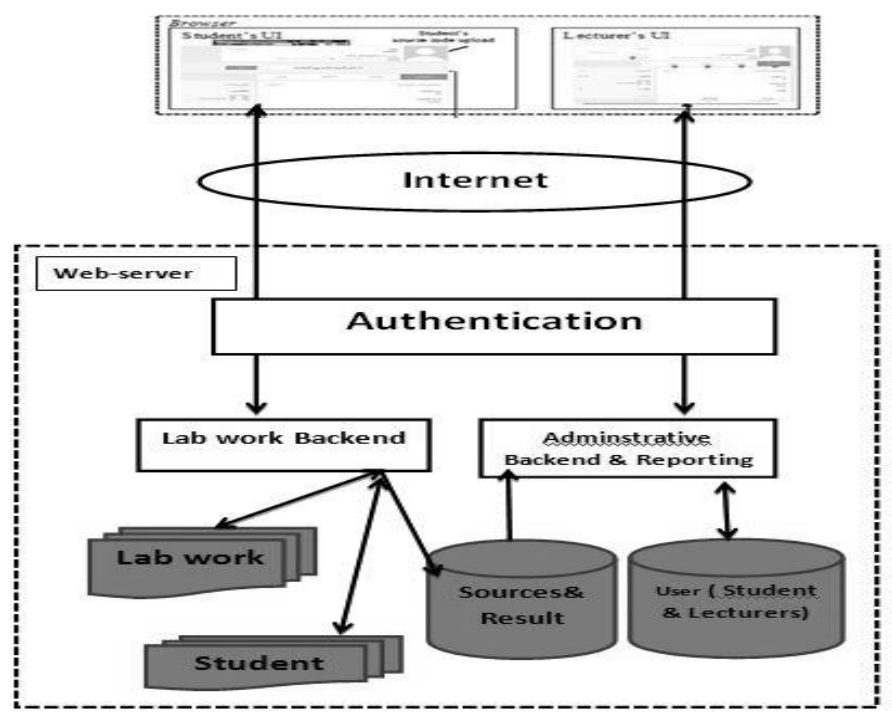

Fige 3:-Architecture of the setting up the VCL in acadox environment. 


\section{Methodology:-}

This study employed a designed experiment methodology that involved the preparation, design, implementation and retrospective analysis of a teaching experiment. A designed experiment is an iterative process that features cycles of invention and revision. The participating teacher worked in close partnership with the author to incorporate the use of VML in lessons, examining the strengths and limitations of existing pedagogy and practice and acknowledging areas for future development with the VML.

\section{Reserch Design:-}

The subjects of the study were 50 students from a secondary school. Each student was trained before the start of the VML. The purpose of the training sessions was primarily to introduce the interface design and to train the participating students in the use of the algebraic, graphical and numerical functions

of VML while engaging the students in inspiring activities involving mathematical problem solving and exploration with the acadox environment.

To determine more precisely, the role of VML in teaching and learning calculus in the participating class, a calculus package focusing on differentiation and integration that integrated VML was designed. The topics covered were Differentiation by First Principles, Equations of the Tangent and the Normal, Rate of Change, Stationary Points, Derivatives of Trigonometric Functions, Derivatives of Exponential and Logarithmic Functions, Integrations and Indefinite Integrals, Definite Integrals, Integration of Trigonometric Functions, Integration of Exponential Functions and $1 / x$, and Area of a Region. It starts with a known pattern: a parabolic, sine or circular. The curves will be shaped by the graphical effect that corresponds to the presence of the parameter $\mathrm{k}$ in the algebraic expression. Different forms and graphical effects are included on considering the mathematical functions listed in Table 1.

Table 1:- Functions and graphical effects considered in the application.

\begin{tabular}{cccc}
\hline Graphical effect & Parabola & Sine & Circle \\
\hline Original & $y=x^{2}$ & $y=\sin x$ & $y=\sqrt{1-x^{2}}$ \\
Vertical scroll & $y=x^{2}+k$ & $y=\sin x+k$ & $y=\sqrt{1-x^{2}}+k$ \\
Horizontal scroll & $y=(x+k)^{2}$ & $y=\sin (x+k)$ & $y=\sqrt{1-(x+k)^{2}}$ \\
Contraction & $y=k x^{2}$ & $y=k \sin x$ & $y=k \sqrt{1-x^{2}}$ \\
Expansion & & $y=\sin k x$ & $y=\sqrt{R^{2}-x^{2}}$ \\
Other & & &
\end{tabular}

The VML learning activities focused on introducing mathematical concepts through exploration using VML. Students were encouraged to examine the setting of a given problem or to manipulate the parameters of a simulation in a VML document that was

$\mathrm{d}$

$d x(\sin x)=\cos x$

\section{Notes:-}

$>$ Use VML to verify the above results. The gradient of the tangent line to $\mathrm{y}=\sin (\mathrm{x})$ at a given point gives the value of the derivative of $y=\sin (x)$ at that point.

$>$ Use the tangent line to trace an approximate graph of the derivative of $y=\sin (\mathrm{x})$. The slope of the tangent is shown at the top right of the screen. Your goal is to move the tangent line by grabbing and dragging the point of tangency such that it is positioned directly above each of the 13 points, beginning with the leftmost point.

$>$ Inspect the resulting scatter plot, which represents the approximate graph of the derivative of the sine function. Write down your observations.

$>$ Use the Graphs and Geometry application to verify your answer.

They were asked to formulate conjectures and examine and confirm those conjectures, culminating in the derivation of a formula, the generalization of the results or the summarization of the underlying concepts. A worksheet was designed to accompany these activities to facilitate guided discovery and inquiry learning. 
In the second category, the students were assigned tasks to reinforce their conceptual understanding using VML. In a typical activity, an exercise consisting problems related to the concept being taught was assigned and students were required to complete the exercise with the aid of VML.

Occasionally, a formative assessment using the 'Quick Poll' function of ACADOX Navigator, which allows the teacher to gather instant feedback from students through the network, was conducted to assess student understanding. Where time permitted, students were invited by the participating teacher to share their solutions or ideas through the use of the 'Presentation' function of ACADOX Navigator. VML Navigator was also used by the participating teacher to monitor the progress of the students in the in-class tasks by periodically viewing their ACADOX screens.

\section{Acadox presents the following functionalities:-}

- Web-intercom:- This functionality allows the user take part in chats within the 3D environment. The records of such chats can be viewed both in the virtual environment and in Acadox server. These records are stored in Acadox's database.

- Registration booth: This functionality allows relating student's avatars to their corresponding Acadox's accounts. It is required because students frequently have different names for their accounts and their avatars which can pose some problems when recording their activities.

- Quiz tool and 3D Drop Box: This functionality allows the students to execute tasks involving the creation of objects in the virtual environment. The objects created are then transferred to Acadox similar to the way a file is uploaded.

- Multi-function Toolbar: This functionality allows the user to activate the blog development function within the virtual environment. Such blogs can be viewed both in the virtual environment and in Acadox.

- Presenter: This functionality allows the users to post in the virtual environment, slideshows or videos that can be viewed or downloaded from the Acadox server.

- Quiz Chair: This functionality allows the students to answer prepared questions in Acadox, which also stores the answers.

All of the activities and accompanying worksheets were designed after thorough discussion with the participating teacher who then co-taught the calculus package with a research assistant of the project who assisted the participating teacher with the use of VML and its Navigator, Activities such as guided discovery.

\section{Data Collection Instruments:-}

A questionnaire was used to measure the quality of the suggested system in a simple way. To make sure of clarity of statements, they were adjusted by some professional professors.

\section{Data Analysis:-}

To analyze the questionnaire statements, SPSS19 was used to extract mean M, standard divination SD and T-test to regard the studied statements as qualitative data for knowing if there is a relationship between science laboratories and their support to the educational process.

\section{Expert's attitudes:-}

The use of SPSS software to make a statistical analysis of the terms of the views of expert's form towards the use of VML system to conduct ,Experiments and the results were as follows: 
Table 2:- Descriptive statistics of Expert's attitudes toward the VML system.

\begin{tabular}{|c|c|c|c|c|c|c|}
\hline $\mathrm{NO}$ & statements & $\mathrm{N}$ & Minimum & Maximum & Mean & $\begin{array}{c}\text { Std. } \\
\text { Deviation }\end{array}$ \\
\hline $1-$ & $\begin{array}{l}\text { The application provides an interactive } \\
\text { environment for students. }\end{array}$ & 30 & 1 & 2 & 1.20 & 0.407 \\
\hline $2-$ & $\begin{array}{l}\text { Application to embody the abstract scientific } \\
\text { concepts helps. }\end{array}$ & 30 & 1 & 2 & 1.07 & 0.254 \\
\hline $3-$ & $\begin{array}{l}\text { Application to improve the level of } \\
\text { understanding among students help, }\end{array}$ & 30 & 1 & 3 & 1.13 & 0.434 \\
\hline 4- & $\begin{array}{l}\text { This application was designed in an interesting } \\
\text { and attractive. }\end{array}$ & 30 & 1 & 2 & 1.10 & 0.305 \\
\hline $5-$ & $\begin{array}{l}\text { Application of self-learning skills of the } \\
\text { learner grown. }\end{array}$ & 30 & 1 & 3 & 1.20 & 0.484 \\
\hline 6- & $\begin{array}{l}\text { This application helps in achieving } \\
\text { educational goals. }\end{array}$ & 30 & 1 & 2 & 1.30 & 0.596 \\
\hline $7-$ & $\begin{array}{l}\text { Application to get good educational outcomes } \\
\text { able to use developments in educational } \\
\text { technology helps. }\end{array}$ & 30 & 1 & 3 & 1.17 & 0.461 \\
\hline $8-$ & $\begin{array}{l}\text { The application software provides simulated } \\
\text { reality. }\end{array}$ & 30 & 1 & 2 & 1.13 & 0.346 \\
\hline 9- & The application meets the needs of the learner. & 30 & 1 & 3 & 1.27 & 0.583 \\
\hline $10-$ & $\begin{array}{l}\text { Application to increase the motivation of } \\
\text { Hamas helps the learner to learn. }\end{array}$ & 30 & 1 & 2 & 1.17 & 0.379 \\
\hline $11-$ & $\begin{array}{l}\text { The application provides an atmosphere of } \\
\text { privacy for students. }\end{array}$ & 30 & 1 & 3 & 1.17 & .0 .461 \\
\hline $12-$ & $\begin{array}{l}\text { The application makes an active and positive } \\
\text { student. }\end{array}$ & 30 & 1 & 2 & 1.03 & 0.183 \\
\hline 13- & $\begin{array}{l}\text { Application on the continuous training of } \\
\text { student helps which helps workmanship. }\end{array}$ & 30 & 1 & 2 & 1.03 & 0.183 \\
\hline 14- & Easy to use for student application. & 30 & 1 & 2 & 1.07 & .0 .254 \\
\hline $15-$ & $\begin{array}{l}\text { The application provides interactive features } \\
\text { with the students. }\end{array}$ & 30 & 1 & 2 & 1.03 & 0.183 \\
\hline
\end{tabular}

"The application provides an interactive environment for students" (M=1.20, SD=0.407), "Application to embody the abstract scientific concepts helps." ( $\mathrm{M}=1.07, \mathrm{SD}=0.254)$, "Application to improve the level of understanding among students help" ( $\mathrm{M}=1.13, \mathrm{SD}=0.434)$, "This application was designed in an interesting and attractive." $(\mathrm{M}=1.10, \mathrm{SD}=0.305)$, "Application of self-learning skills of the learner grown." $(\mathrm{M}=1.20, \mathrm{SD}=0.484)$, "This application helps in achieving educational goals." $(\mathrm{M}=1.30, \mathrm{SD}=0.596)$, "Application to get a good educational outcomes able to use developments in educational technology helps." (M=1.17, SD=0.461), "The application software provides simulated reality." $(\mathrm{M}=1.13, \mathrm{SD}=0.346)$, "The application meets the needs of the learner." $(\mathrm{M}=1.27, \mathrm{SD}=0.583)$, "Application to increase the motivation of Hamas helps the learner to learn." $(\mathrm{M}=1.17, \mathrm{SD}=$ 0.379), "The application provides an atmosphere of privacy for students." ( $\mathrm{M}=1.17, \mathrm{SD}=0.461)$, "The application makes an active and positive student." $(\mathrm{M}=1.03, \mathrm{SD}=0.183)$, "Application on the continuous training of student help which helps workmanship." ( $\mathrm{M}=1.03, \mathrm{SD}=0.183)$, "Easy to use for student application." $(\mathrm{M}=1.07, \mathrm{SD}=0.254)$, "The application provides interactive features with the students." (M=1.03, SD=0.183).

- The views of students' attitudes: A field study focused on the importance of VML system in the laboratory of traditional real to the stage of a secondary school where the number of students involved in this experiment are 50 students of a secondary school simulation was conducted. Data were collected by the views of a questionnaire to gauge the views of students about the use of the proposed VML system includes wage trial on four steps:

The first step: Students have been creating content for laboratory experiments by having competent to rule clarification and guidance to the students' action steps prescribed by the laboratory tests that were true through most of the meeting between the competent and students. 
The second step: The students were trained on how to use the VML and guide students in dealing with the system pragmatic system pragmatics, by training students on how to enter the system, and keep track of work experience measures and how to move from a chemical experiment to another.

The third step: The students to re-do the experiments using the proposed application. The role of the researcher and competent to rule at this stage, is to follow the progress of students in work experience, and providing assistance to them, and answering questions raised by students during the experiment At the end of each experiment, there was a discussion with the students about what is implementation.

Step Four: A questionnaire was distributed to measure the views towards the use of VML system to conduct experiments.

\section{B. Results:}

The use of SPSS software to make a statistical analysis of the terms of the views of students form towards the use of VML system to conduct experiments and the results were as follows:

Table 3:- Descriptive statistics of student's attitudes toward the VML system.

\begin{tabular}{|c|c|c|c|c|c|c|}
\hline $\mathrm{NO}$ & statements & $\mathrm{N}$ & Minimum & Maximum & Mean & $\begin{array}{c}\text { Std. } \\
\text { Deviation }\end{array}$ \\
\hline $1-$ & VML is a new teaching method & 50 & 1 & 2 & 2.62 & 0.490 \\
\hline $2-$ & Help install information. & 50 & 1 & 2 & 2.48 & 0.505 \\
\hline 3- & Easy to use. & 50 & 1 & 2 & 2.60 & 0.495 \\
\hline 4- & Makes the learner's active and positive. & 50 & 1 & 2 & 2.48 & 0.677 \\
\hline 5- & It provides the use of a suitable environment. & 50 & 1 & 2 & 2.38 & 0.667 \\
\hline 6- & Provide interactive experiences. & 50 & 1 & 2 & 2.56 & 0.611 \\
\hline 7- & Offer to extract information. & 50 & 1 & 2 & 2.56 & 0.577 \\
\hline 8- & Take into account individual differences. & 50 & 1 & 2 & 2.44 & 0.611 \\
\hline 9- & $\begin{array}{l}\text { It provides an opportunity to work outside the } \\
\text { formal learning tools. }\end{array}$ & 50 & 1 & 2 & 2.60 & 0.571 \\
\hline $10-$ & It helps to learn many skills in a short time. & 50 & 1 & 2 & 2.72 & 0.454 \\
\hline $11-$ & $\begin{array}{l}\text { It provides an opportunity to end the learning } \\
\text { process according to your own pace and his } \\
\text { ability to learn. }\end{array}$ & 50 & 1 & 3 & 2.56 & 0.577 \\
\hline $12-$ & Grown self-learning skills. & 50 & 1 & 2 & 2.62 & 0.490 \\
\hline $14-$ & $\begin{array}{l}\text { This application is an advanced technical } \\
\text { system and is important to face the challenges } \\
\text { of the times. } \\
\text { The application provides the privacy of } \\
\text { student. } \\
\text { Application to understand the information } \\
\text { deeper help. }\end{array}$ & 50 & 1 & 2 & 2.34 & 0.626 \\
\hline 16- & It helps to learn and absorb mathematics. & 50 & 1 & 2 & 2.64 & 0.485 \\
\hline $17-$ & $\begin{array}{l}\text { Encouraged to overcome the negative } \\
\text { reception of information to active participation } \\
\text { in education. } \\
\text { Encourages the application on the stimulus } \\
\text { and preview the information and control. }\end{array}$ & 50 & 1 & 2 & 2.54 & 0.579 \\
\hline & & & & & & \\
\hline
\end{tabular}

The Alpha physical coefficient was calculated about student attitudes towards VCL system, It gave the highest score of acceptance $(\mathrm{a}=0.898)$. It was also found that students showed their acceptance that VML is a new teaching method $(M=2.62, S D=0.490)$ and that Help install information. $(M=2.49, S D=0.505)$ and that easy to use. (M=2.60, 
$\mathrm{SD}=0.495)$. Makes the learner's active and positive. $(\mathrm{M}=2.48, \mathrm{SD}=0.677)$ and It provides the use of a suitable environment. $(\mathrm{M}=2.38, \mathrm{SD}=0.667)$. Provide interactive experiences. $(\mathrm{M}=2.56, \mathrm{SD}=0.611)$.

Students also agreed that Offer to extract information. $(\mathrm{M}=2.56, \mathrm{SD}=0.577)$. There was also taking into account individual differences. $(\mathrm{M}=2.44, \mathrm{SD}=0.611)$, It provides an opportunity to work outside the formal learning tools. $(\mathrm{M}=2.60, \mathrm{SD}=0.571)$ and It helps to learn many skills in a short time. $(\mathrm{M}=2.72, \mathrm{SD}=0.454)$.

It also provides an opportunity to end the learning process according to your own pace and his ability to learn. $(\mathrm{M}=2.56, \mathrm{SD}=0.577)$, It also Grown self-learning skills. $(\mathrm{M}=2.62, \mathrm{SD}=0.490)$. This application is an advanced technical system and is important to face the challenges of the times. $(\mathrm{M}=2.72, \mathrm{SD}=0.454)$. The application provides the privacy of student $(\mathrm{M}=2.34, \mathrm{SD}=0.626)$. Application to understand the information deeper help $(\mathrm{M}=2.38$, $\mathrm{SD}=0.753)$. It helps to learn and absorb mathematics. $(\mathrm{M}=2.64, \mathrm{SD}=0.485)$. Encouraged to overcome the negative reception of information to active participation in education. $(\mathrm{M}=2.54, \mathrm{SD}=0.579)$. Encourages the application on the stimulus and preview the information and control $(\mathrm{M}=2.60, \mathrm{SD}=0.571)$.

\section{Comparison between RML and VML:-}

The comparison of Real Mathematic Lab (RBL) and Virtual Mathematic Lab (VBL) the terms of learning performance and the factor of learning time.

\section{Comparison of learning performance:-}

In this selection, we want to understand whether or not there is a difference between learning methods. This research employs a T-test to analyze the relation between students' "pre-examination achievement", "post-examination achievement" and "learning model (VML)".

Table 4:- Results of the t-test between pre-test and post-test regarding Comparison of learning performance.

\begin{tabular}{|c|c|c|c|}
\hline Group & Mean & $\begin{array}{c}\text { Standard } \\
\text { deviation }\end{array}$ & t-test \\
\hline Pre-test & 11.87 & 3.09 & 5.685 \\
\hline Pro-test & 14.91 & 2.27 & \\
\hline
\end{tabular}

Table 4. Shows that the results of the t-test shows there was a statistically significant difference between the pre-test $(M=11.87)$ and the post-test $(M=14.91)$. In terms of VML application, where we find T-TEST $=5.685$

\section{Learning Time:}

In this selection, we want to understand whether or not there is a difference learning time between in RML and VML, This research employs an ANOVA to analyze the relation between VML, RML

\section{ANOVA}

Table 4. ANOVA result for assessment learning time between in RML and VML

\begin{tabular}{|l|r|r|r|r|r|}
\hline & Sum of Squares & df & Mean Square & F & Sig. \\
\hline Between Groups & 568.367 & 23 & 24.712 & .982 & .562 \\
\hline Within Groups & 151.000 & 6 & 25.167 & & \\
\hline Total & 719.367 & 29 & & & \\
\hline
\end{tabular}

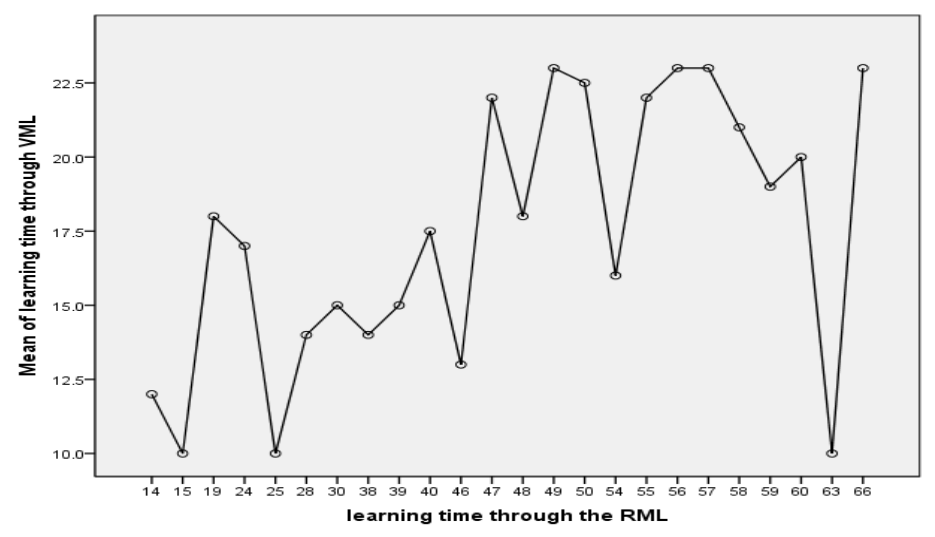


On average, there was a significant difference in the percentage learning time, where we find that the average learning time through the RML (Mean= 44.47), while we find learning time through VML (Mean=17.03), from indicates the effectiveness of the system in reducing the learning time.

\section{Discussions:-}

The results of the study support the research hypothesis that the new mathematical experiences afforded by VML offer students a rich setting to explore calculus concepts. The dynamic features of graphing calculators, such as multiple representations of mathematical concepts, if used appropriately, can improve students' ability to make the connection between graphical and algebraic representations. This feature was found to be particularly useful in teaching and learning calculus.

Many ways of using VML as a tool in the mathematics classroom were identified in this study. In the Simulation programme, VML was used as an exploratory tool, graphing tool, confirmatory tool, problem-solving tool, visualization tool and calculation tool. Underlying these uses was the pedagogy of the design of the mathematical tasks and the interaction between the students and the tasks designed for use with VML.

Zacharia et al. [9] theorized four roles for technology in relation to teaching and learning interactions: master, servant, partner and extension of self. In the current study, uses of VML as a confirmatory tool, a calculation tool or a graphing tool by the students certainly have characteristics of the servant role while uses of VML as an exploratory tool, a problem-solving tool or a visualization tool illustrate using the technology as a partner. It was evident that students in this study were able to use VML beyond the level of using it as a master as it was clear that the students were not 'subservient to the technology'. However, there was insufficient evidence to suggest that they could use the technology as an extension of self, the highest level of functioning which involves 'users were incorporating technological expertise as an integral part of their mathematical repertoire'. On the other hand, Lampi [10] found five patterns and modes of graphing calculator tool use: computational tool, transformational tool, data collection and analysis tool, visualizing tool and checking tool. While students in this study used VML as a computational tool in evaluating numerical expressions, and as a checking tool in confirming conjectures.

Analysis of the interviews with the students from the participating class on theConcept of the derivative at a point revealed that the use of VML, and particularly its emphasis on visual and numerical representations of the derivative, affected the students' conceptual development. Students interviewed were able to find the derivative of a given function using a visual conception of the derivative that they had learned in the intervention programme. This finding suggests that the students were able to form connections between the different representations of the derivative in calculus using VML, which helped them to develop a conceptual understanding of the derivative. The conventional teaching and learning of mathematics over-emphasizes algebraic methods, and the students had been trained to use such methods to solve most mathematics problems. However, the use of a graphing calculator can change the teaching and learning of calculus concepts from relying solely on algebraic method to encompassing numeric, algebraic and graphical methods, as indicated by Elizondo [11]. Several studies have shown that the connection of International Journal of Mathematical Education in Science and Technology different representations leads to the development of conceptual understanding and the improvement of students' problem-solving skills [12].

It was found that some of the students claimed that they have been taught mainly using algebraic methods since they were young. Thus, the predominant approach that they used in problem solving remained algebraic even after using VML, although they saw the usefulness of the graphical approach in solving problems and understanding concepts better. Some even claimed that they only realized the accuracy and efficiency of the graphical method in problem solving after the intervention programme. These findings suggest that the use of a graphing calculator should be integrated into mathematics teaching and learning at an early stage, such as Secondary Stage.

Teachers play an important role in conventional mathematics teaching and learning in the classroom. Most of the time, they are in full control of the teaching and learning situation and act as the knowledge provider. However, the teacher's role changes when VML is used in the classroom from an instructor to a learning facilitator. Students play an active role in the learning process, and construct their learning through guided discovery and inquiry-based learning tasks that they can then share using VML Navigator.

The visualization aspect of VML engendered a better conceptual understanding through demonstrating graphs and simulations. In addition, the mathematical tasks were designed in a way that facilitated students' learning. The 
conventional mode of learning that focuses on the regurgitation of what teachers have taught does not necessarily allow students to gain a full understanding of concepts, which are of utmost important in calculus.

\section{Conclusions:-}

The findings from this research demonstrate the potential of VML as a tool to promote learning in mathematics. The encouraging results recommend the use of the graphing calculator to provide multiple representations for mathematics learning and problem solving. A framework is also proposed that shows the importance of the interactions among the students, VML, and the learning tasks in the learning of calculus. In the future, VML could be used to stimulate students to think mathematically so that they will engage strongly with mathematical structures and concepts in ways that are not possible with traditional paper and pencil approaches. However, before it is used for this purpose, training should be provided so that teachers and students can become familiar with the features and functions of VML as a pedagogical tool.

\section{References:-}

1. Algozzine, B., Chuang,W.,\&Violette,A."Reexamining the relationship between academic achievement and social behavior", Journal of Positive Behavior Intervention, 13(1), (2010):3-6.

2. Amunga, K. \&Musasia, A. "Disparities in mathematics achievement among secondary schools: The case of Kenya", Problems of Education in the $21 \mathrm{~s}$ 'Century, 25(1), (2011): 8-18.

3. Blake, C., \& canlon, E. "Reconsidering simulations in science education at a distance: Features of effective use", Journal of Computer Assisted learning, 23(6), (2007): 491-502.

4. Chu, H.C., Hwang, G.J. and Tsai, C.C. "A knowledge engineering approach to developing mindtools for context-aware ubiquitous learning", Computers \& Education, Vol. 54, No. 1, (2010):289-297.

5. Dega, B.G., Kriek, J. and Mogese, T.F. "Students' conceptual change in electricity and magnetism using simulations: a comparison of cognitive perturbation and cognitive conflict", Journal of Research in Science Teaching, Vol. 50, No. 6, (2013):677-698.

6. Hung, I.C., Yang, X.J., Fang, W.C., Hwang, G.J. and Chen, N.S. "A context-aware video prompt approach to improving in-field reflection levels of students", Computers \& Education, Vol. 70, No. 1, (2014):80-91.

7. Beal, C., Adams, N., \& Cohen, P. "Reading proficiency and mathematics Problem solving by high school English language learners". Urban Education, 45( 1), (2010): 58-74.

8. Lazonder, A. W., Hagemans, M. G., \& de Jong, T. "Offering and discovering domain information in simulation-based inquiry learning", Learning and Instruction, 20(6), (2010): 511-520.

9. De Jong, T., Linn, M. C., \& Zacharia, Z. C. "Physical and virtual laboratories in science and engineering education", Science, (2013): 305-308.

10. Lampi, E" The Effectiveness of Using Virtual Laboratories to Teach Computer Networking Skills in Zambia", PhD thesis, Virginia Polytechnic Institute and State University.( 2013):56

11. Elizondo-Omana, R. "Traditional teaching supported by computer-assisted learning for macroscopic anatomy", The Anatomical Record (New Anatomist), 278(1), (2004):18-22.

12. Khalil, M., Johnson, T., \& Lamar, C. " Comparison of computer-based imagery strategies in learning anatomy", Clinical Anatomy, 18, (2005): 457-464.

13. Srisawasdi, N. "Student teachers' perceptions of computerized laboratory practice for science teaching: a comparative analysis", Procedia: Social and Behavioral Sciences, ol. 46, (2012): 4031-4038

14. Srisawasdi, N., \& Kroothkeaw, S. "Supporting students' conceptual learning and retention of light refraction concepts by simulation-based inquiry with dual-situated learning model", Journal of Computers in Education, 1(1), (2014): 49-79.

15. Vreman-de Olde, C., de Jong, T., \& Gijlers, H. "Learning by designing instruction in the context of simulationbased inquiry learning", Educational Technology \& Society, 16(4), (2013): 47-58.

16. Vreman-de Olde, C., de Jong, T., \& Gijlers, H. "Learning by designing instruction in the context of simulationbased inquiry learning", Educational Technology \& Society, 16(4), (2013): 47-58.

17. W.L. Ng, W.C. Tan, and M.L. Ng."Teaching and learning calculus with the TI-Nspire: A design experiment",in Proceedings of Asian Technology Conference in Mathematics,T. Alwis, M. Majewski, and W.C. Yang, eds., Beijing Normal University, Beijing, (2009): 345-356. 